Fecha de recepción: febrero 2018 Fecha de aceptación: abril 2018 Versión final: diciembre 2019

\section{Nuevas tramas socio-espaciales después de la inundación en la ciudad de La Plata: un análisis de experiencias artísticas y memoria colectiva}

Verónica Capasso *

Resumen: En el marco de tematizar la inundación ocurrida en la ciudad de La Plata -Buenos Aires, Argentina-, el 2 de abril de 2013, esta investigación propone abordar diversas prácticas artísticas colectivas que produjeron marcas de memoria en el espacio público. A partir de la aparición y del despliegue en múltiples tipos de materialidades, estas propuestas artísticas se instituyeron como instrumentos para la reflexividad sobre la catástrofe. Se examinarán las características propias de las elecciones estéticas, de disputas entorno a la ubicación y al tipo de representaciones generadas, como también sobre las luchas por la construcción de una memoria colectiva que cuatro años después sigue vigente.

Palabras clave: Prácticas artísticas - Marcas de memoria - Inundación - La Plata - Espacio público.

[Resúmenes en francés, inglés y portugués en la página 35]

${ }^{(*)}$ Magister en Ciencias Sociales y Doctoranda en Ciencias Sociales, Profesora en Historia del Arte, orientación artes visuales y Licenciada en Sociología por la Universidad Nacional de La Plata -UNLP-. Posee un Diploma en Cultura Brasileña -Universidad de San Andrés-. Actualmente es Ayudante diplomada en la cátedra Cultura y sociedad del Profesorado en Portugués de la UNLP. Ha publicado numerosos trabajos académicos en el marco de su trabajo de investigación en Sociología e Historia del Arte.

\title{
Introducción
}

El 2 de abril de 2013 la ciudad de La Plata -capital de la Provincia de Buenos Aires-, sufrió la peor inundación de su historia dejando innumerables secuelas económicas, sociales, psicológicas y políticas. Llovieron casi 400 milímetros en muy pocas horas -más del doble que el promedio de todo el mes-, rompiendo con ello los registros históricos. La inundación fue desigual, ya que algunos barrios fueron más perjudicados que otros como la mayor parte del casco fundacional que quedó anegado.

La nómina oficial de la Localidad reconoció 52 muertos mientras que la causa del Juez Arias registró 89 y la cifra final que expuso la investigación de López Mc Kenzie y Soler (2014) asciende a 109 muertos, incorporando a quienes fallecieron por falta de luz en los hospitales, por estrés, por ACV, por depresión y por enfermedades de transmisión hídrica. 
La inexistencia de medidas de seguridad para contrarrestar el estado de emergencia civil sirvió para darle más realce a una constatación de importancia pública: los efectos devastadores de la falta de planificación urbana y la ausencia de una reflexión, en torno a la sustentabilidad de los cambios estructurales propiciados.

Es preciso decir que si bien desde su fundación en 1882, La Plata se diseñó y planificó caracterizándose por una estricta cuadrícula con avenidas y diagonales, esta concepción de ciudad ha sido reinterpretada a lo largo del tiempo, con lo cual se constituyó un espacio urbano en el que los vínculos entre los poderes públicos, la gestión del territorio y la sociedad civil fueron y son promovidos en relación con metas y objetivos muchas veces disímiles. A medida que la población creció, esta programación urbana fue cada vez menos eficaz, producto de las reglas del mercado, y la especulación inmobiliaria desconsiderando una planificación estatal sustentable e integral ocupando -formal e informalmente-, áreas de alto riesgo ambiental.

La ciudad se encuentra sobre la cuenca hídrica del Río de la Plata, con los arroyos El Gato, Regimiento, Pérez, Maldonado, Garibaldi y sus respectivas ramificaciones rodeados de viviendas. En suma y lejos de pensar en términos integrales, el crecimiento urbano en beneficio de la comunidad se contribuyó a la concentración edilicia en el casco urbano, lo que produjo el incremento de problemas de degradación urbana, contaminación sonora, déficit de infraestructura básica, en torno a los servicios públicos -luz, agua, entre otros-, y aumentando la superficie construida en detrimento de zonas verdes o de fácil y rápida absorción de agua de lluvia. A su vez, muchos barrios han crecido alrededor de los arroyos y no se han hecho las obras de entubamiento pertinentes.

Retomando, si bien los efectos de la inundación fueron catastróficos, durante y después de la inundación se desplegaron múltiples formas de solidaridad en la escena pública y diferentes prácticas y estrategias de acción y organización social, entre ellas las artísticoculturales. Estas últimas contribuyeron a generar espacios de narración -verbales, visuales- de la experiencia traumática, ya sea en espacios institucionales -como lo fueron los museos de arte de la Ciudad-, como en la vía pública urbana.

En este artículo, trabajaremos con tres casos desplegados en el espacio público: el Monumento a las Víctimas de la Inundación de la Asamblea Vecinal Parque Castelli, las intervenciones de La Marca del Agua y el trayecto performático de una marcha, realizada por el colectivo artístico "Volver a habitar" junto a los colectivos "Intervenir LP" y "La Joda teatro", a los que se le sumaron vecinos, artistas de la Ciudad, familiares de víctimas de la inundación y la Asamblea de Asambleas barriales. Las propuestas aquí analizadas produjeron una memoria sobre los hechos a los cuales refirieron y a su vez, estas prácticas, no sólo cristalizaron modos particulares de recordar y de reactualizar lo sucedido, sino que también supusieron compartir lazos y solidaridades. En este sentido, configuraron nuevas tramas socio-espaciales constituyéndose como marcas de memoria, siendo unas más efímeras y otras permanentes, a la vez que en determinadas fechas, algunas de ellas se re-actualizaron.

En suma, consideramos que, por un lado, el espacio social no es una tabula rasa sino que se trata siempre de una superficie señalada por una infinidad de marcas del pasado, las cuales son "centros mnemónicos" o puntos de referencia para el recuerdo (Giménez, 2009, p. 22). Por otra parte, el arte, aquí aparece como portador de memoria y permite el montaje de 
tiempos heterogéneos (Oviedo, en Didi-Huberman, 2006): el pasado al referir un hecho, la experiencia del presente y el porvenir en los procesos de reactualización que buscan evitar el olvido. Es decir, la dimensión espacial y temporal son centrales, como veremos en la construcción de memoria colectiva.

Por último, metodológicamente, el fenómeno a estudiar cruza los campos de los estudios sociales del arte y los estudios de la memoria proponiendo un punto de vista transdisciplinario que implica una mirada compleja de la relación entre el proceso político social y las producciones artísticas. Al respecto, es pertinente la formulación de Giunta de conectar lo artístico con procesos culturales más amplios (Richard, 2014). En virtud de ello, nos posicionamos desde la idea de la existencia de un campo cultural expandido, ampliando la teoría de los campos disciplinares tradicionales. Debido a ello, el análisis se realizará a partir de una metodología de corte cualitativo. De este modo, recurrimos a observaciones participantes y no participantes de las prácticas artísticas y a entrevistas.

El relato se estructura de la siguiente forma: Abordaremos algunos tópicos centrales respecto a la memoria. No es nuestra intención sumergirnos en este amplio y complejo tema sino que nos interesa recuperar algunas herramientas conceptuales que nos permitan, en un segundo momento del trabajo, examinar un corpus de producciones artísticas post inundación. Por último, concluiremos que diversas prácticas y marcas de memoria, cuyos procesos han sido diferenciales, coincidieron en plantearse como objetivo para activar dinámicas de significación y lectura ciudadanas sobre la inundación. A través de la aparición y del despliegue en múltiples tipos de materialidades -lugares, trayectos urbanos de marchas, manifestaciones virtuales, cuerpos, etc.-, estas propuestas artísticas se instituyeron como instrumentos para la reflexividad sobre la catástrofe. Así, de la mano del arte como "una potencia de significación" (Richard, 2010, p. 187), se ha podido visualizar el "movimiento de la memoria" (Schindel, 2009).

\section{Memorias, arte, espacios y tiempos}

El campo de la historia y la memoria es profuso y existen distintos autores que se han abocado a responder las siguientes preguntas: ¿Qué es la memoria?, ¿quién recuerda?, ¿qué se recuerda?, ¿cómo pensar lo social en los procesos de memoria? También existen planteos acerca de la dificultad de cómo se representa la memoria, quién dice, qué memorias son representadas, qué memorias quedan fuera, cuáles memorias entran en conflicto, cómo podemos traducir una experiencia de tipo traumático. Al respecto, es relevante la idea de que existen momentos propicios para que los recuerdos sean expresados y ello se vincula con que existan personas con capacidad de escuchar esas experiencias. Muchos de los desarrollos teóricos sobre el tema se centraron en relación al pasado reciente -por ejemplo, al Holocausto o, en nuestro país, a la última dictadura cívico militar- y, si bien no es el contexto aquí abordado, sí podemos repensar algunos conceptos como herramientas teóricas a la luz de nuestros casos.

En primer lugar, partimos de entender la memoria como categoría social (Jelin, 2001), es decir, como la facultad que excede el nivel individual para comprenderse enmarcada socialmente siendo un proceso constante e indefinido de resignificación. La memoria social 
se constituye a partir de experiencias vividas por grupos sociales, "se articula con la oralidad, la pluralidad y la sociedad civil" (Lifschitz, 2012, p. 2) y, "por eso, la memoria es del orden del lazo social" (Lifschitz, 2012, p. 3), y se relaciona con compromisos emocionales y políticos.

En segundo término y siguiendo a Pollak (1989), la memoria está compuesta por acontecimientos-vividos personalmente o por el grupo al cual la persona siente que pertenece-, por sujetos y lugares particularmente relacionados con el recuerdo. Además, es selectiva, ya que no registramos todo. En parte es heredada, excediendo el tiempo de la vida física de la persona y también posee una perspectiva de futuro; por ello, la dimensión temporal es relevante, en tanto, como sostiene Jelin (2017), la memoria es la manera en que los sujetos construyen un sentido del pasado, un pasado que se actualiza con el presente y también con un futuro deseado - un horizonte de expectativas-, en el acto de rememorar, olvidar y/o silenciar.

En tercer lugar, nos interesa retomar la propuesta de Halbwachs (1990) quien establece una relación entre espacio y memoria bajo la idea de que la memoria colectiva no existe al margen de un marco espacial que le da sentido. Para el autor, todo grupo y actividad colectiva están ligados a un espacio específico, el cual es transformado mediante actos de apropiación. Existe entonces una relación entre grupos y espacios que se van modificando y/o transformando por sucesos, que al ser extraordinarios, pueden alterarla. Asimismo, la memoria no sólo se halla asociada a un marco espacial concreto sino también a un momento temporal específico; es decir, al contexto social y político en el que emergen las marcas -en nuestro caso la post inundación-. Es mediante diversos tipos de marcas que se expresa el recuerdo y se intenta transmitir a otros una memoria colectiva y social. Así, estas marcas pueden servir de referencia para las generaciones posteriores y también a públicos no familiarizados con el tema mediante la evocación de un hecho.

Ahora bien, además de considerar que la memoria es una construcción individual y colectiva, que posee una dimensión temporal -de pasado, presente y futuro-, y que se vincula con el espacio, focalizaremos en este artículo en dos conceptos centrales: marcas de memoria y vehículos de memoria. Las marcas de memoria pueden adoptar distintas formas: monumentos, placas, baldosas, plazas, nombres de calle, esculturas, fotografías y algunas pueden ser efímeras como las performances.

Es interesante considerar que la marcación de espacios de memoria no siempre se produce con una intención definitiva sino que puede ser el resultado de prácticas breves y/o fugaces. Es el caso, por ejemplo, de una manifestación o un acto de homenaje. Recuperando a Schindel (2009), podemos hablar de tres tipos de marcas: los sitios testimoniales-sedes de crímenes humanitarios y violaciones de los derechos humanos-, los monumentos, museos y memoriales -como otros espacios de conmemoración-, y las estrategias locales, descentralizadas y/o performativas de marcación de la memoria en el espacio. Estas últimas son aquellas prácticas que resultan efímeras y suponen intervenciones en el espacio público por un determinado lapso de tiempo, materializándose el recuerdo en las prácticas mismas de los actores sociales, en sus cuerpos.

Por otra parte, será útil el concepto de vehículos de memoria (Jeling y Langland, 2003) para referirnos a cómo la memoria se corporiza en diversos productos culturales -como libros, museos, monumentos, películas, murales, fotografías, etc.-; es decir, las vías por las que se transmiten las memorias, las historias del pasado que adquieren significados 
en el presente como las fechas importantes para un sujeto, los aniversarios y/o las conmemoraciones. En suma, el uso de las nociones de marcas y de vehículos de memoria como herramientas conceptuales son relevantes en tanto nos permiten abordar los diferentes tipos de propuestas artísticas y las distintas formas que pueden adoptar los modos que se va dando la sociedad de recordar.

En las propuestas artísticas, muchas veces puede haber divergencias en los modos de representación de los hechos traumáticos, lo cual muestra la dificultad y variedad de formas que existen sobre cómo se representa la memoria, desde qué discurso nos posicionamos, qué memorias son visibilizadas, cómo podemos traducir una experiencia tan trágica en algo materializado y cómo re-significarla a través del paso del tiempo. Podemos manifestar entonces que las producciones artísticas vinculadas con la memoria, en algunos casos, permiten indagar sobre un suceso, pues suelen no limitarse a registrar sino que muchas veces habilitan poner en juego diversas variables que hacen a una memoria activa. A su vez, el acontecimiento traumático queda ligado a cómo representar determinado hecho, bajo qué formas y cuáles son las maneras y límites que tiene el arte de aproximarse al horror o trauma. Igualmente, es importante tener en cuenta, como sostiene Foster (2002), que la memoria se plantea como un campo de batalla, conflictivo, nunca neutral, ni objetivo y que "hay representaciones mejores y peores, pero no hay una representación correcta" (Huyssen, en Gianera, 2002, p. 27).

$\mathrm{Al}$ respecto, las producciones estéticas pueden ser pensadas como una estrategia, como "vehículos" donde la memoria es un proceso de creación de significados, esencial en la construcción de identidad individual y colectiva. Para Nelly Richard (2007), "sólo una escena de producción de lenguajes permite quebrar el silencio traumático de la no palabra cómplice del olvido (...). Imágenes y palabras, formas y conceptos, ayudan a trasladar la resignificación de la experiencia a planos de legibilidad" (p. 147).

En síntesis, el recurso artístico empleado y la forma en que se plasma no siempre es la misma. La cultura crea nuevas formas de expresar y esto también incluye nuevas formas de representación de la memoria (Battiti, 2007). Muchas de estas estrategias se constituyen como marcas societales -en oposición a las marcas territoriales oficiales o diseñadas desde el Estado-, que proponen la participación ciudadana y algunas -las de carácter performático, por ejemplo- se agotan en la acción del momento. Pero otras aún perviven disputando espacios y sentidos en las especialidades, como es nuestro de observación, en la ciudad de La Plata. Son señales en la calle, en paredes anónimas o en edificios públicos, espacios de territorialización de la memoria, iniciativas que tienen el objetivo de que se mantenga el recuerdo vivo, activo, para que no vuelva a repetirse. A continuación analizaremos tres casos cuyas prácticas artísticas han referido a la inundación en distintos espacios y desde diferentes dispositivos estéticos.

\section{Monumento a las Víctimas de la Inundación de la Asamblea Vecinal Parque Castelli}

La Asamblea Vecinal Parque Castelli se conformó a los pocos días de sucedida la inundación. Entre sus múltiples acciones -entre las que encontramos la realización de murales y un li- 
bro-, la Asamblea realizó un monumento en conmemoración a quienes fallecieron a raíz de la inundación. La obra, ideada por un vecino artista del barrio, fue emplazado en el Parque Castelli, espacio donde la Asamblea se reúne cada quince días y todos los días 2 de cada mes. La escultura está compuesta por manos de distintos tamaños, hechas con hierro recolectado en el barrio representando manos de mujeres, hombres, niños y personas mayores, que buscaron la superficie ante la correntada del agua (Ver Figura 1). La propuesta fue identificar a las diversas personas que se ahogaron. Este modo de representación de las manos, puede ser leído en primer lugar, como el último gesto entre la vida y la muerte, sin distinción de sexo o edad. En segundo término, paradójicamente, también habilita una lectura en donde las manos en alto refieren a la modalidad de voto de una asamblea. Por otro lado, se rodeó al monumento con un jardín con plantas y una placa de mármol que describe el para qué se hizo, cuándo y quién lo realizó. También se marca la fecha estatuida como origen de la Asamblea:

Primer monumento en homenaje a las víctimas fatales de la tragedia evitable del 2 de abril de 2013.

Inaugurado el 19 de octubre de 2013.

Asamblea Vecinal Parque Castelli.

Autor: Carlos Franchimont.

Juntos desde el 9-4-13.

Esta iniciativa no sólo ofició como una manera de recordar a los fallecidos tras la inundación, sino que también operó como un lugar de recuerdo material al cual se llevaban flores y se rezaba, generando un espacio considerado "sagrado", altamente ritualizado. Como ya dijimos, una cuestión importante a tener presente es que el debate estético también es parte constitutiva de los procesos de memoria. Así, puede haber mensajes que sean claros y literales, basados en una estética mimética y descriptiva. También existen aquellos más ambiguos con el objetivo de llamar la atención o despertar la curiosidad y la libre interpretación del espectador. En otras ocasiones puede haber una identificación no buscada con la imagen que instituye la marca o el monumento de memoria. Esto último sucedió con la representación de las manos en el Monumento a las Víctimas de la Inundación. Carlos, asambleístas y quien ideó su forma, relata que:

En el monumento hay dos manos. A mí me pareció que podía ser una pareja, él trató de salvarla a ella y se ahogaron los dos. Y es una mano agarrándose de la otra. Bueno eran justo los padres de Rocío Aguirre (familiar de víctimas de la inundación). Y ella se molestó cuando yo dije eso. Después hablamos de forma personal y terminamos que el año que viene ella quiere que yo le haga un monumento cerca de la casa que simbolice a los padres (Entrevista a Carlos, 22/12/2016).

En este ejemplo se ve un caso de identificación no buscada entre lo que se quiso representar como una escena posible de haberse vivido aquella noche trágica y un hecho que realmente ocurrió. Si bien se ha privilegiado un lenguaje figurativo -a partir de las manos-, no 


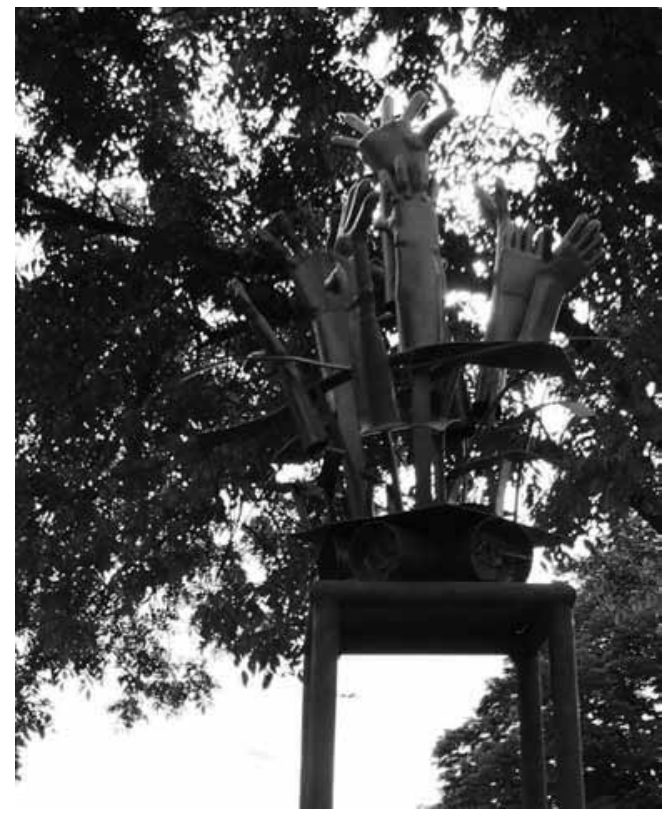

Figura 1. Detalle Monumento a las Víctimas de la Inundación (Asamblea Vecinal Parque Castelli, Parque Castelli, 2013).

es posible generar una asociación directa entre la representación y la singularidad biográfica de las víctimas de la inundación. Esta situación generó roces entre los asambleístas y un familiar de víctimas de la inundación, ya que mientras los primeros buscaban producir una imagen anónima o general -que por la variedad de tamaños y formas apelaba a "que no se estereotipara con algún fallecido específico" (Entrevista a Carlos, 22/12/2016)-, el familiar la veía personalizada y particular, acorde a su vivencia. Por otra parte, aparece aquí una imagen del dolor, de aquellos que murieron ahogados, una imagen que muchos vecinos de La Plata rememoran haber visto esa noche trágica.

Por otro lado, el monumento no sólo funciona como punto de encuentro y de reunión de la Asamblea sino que cada 2 de abril, en un nuevo aniversario de la tragedia, se realiza allí un homenaje a las víctimas. Este acto de reactualización de la memoria se viene haciendo desde hace ya cuatro años. Luego, los asambleístas, vistiendo las remeras que los identifica como tales, se movilizan a la Plaza Moreno para unirse a la marcha general que se realiza cada año. Por ejemplo, el 2 de abril de 2017, se han colocado globos y paraguas negros en el monumento en alusión a las víctimas. Al respecto, podemos decir que la conmemoración -que en este caso ocurre en una fecha clave, relativa al aniversario de la inundación o al segundo día de cada mes- es ante todo una acción para el presente que busca constituir un proceso actual de identificación -en tanto damnificados- y que además, como horizonte de expectativas, pretende que el hecho que se rememora no vuelva a ocurrir. Es por ello que las fechas, los aniversarios y las conmemoraciones también pueden ser vehículos de la memoria. 


\section{Acciones performáticas de La Marca del Agua}

El colectivo La Marca del Agua surgió en junio de 2013 a raíz de la Feria del Libro que la Municipalidad de La Plata organizó en el Pasaje Dardo Rocha. Un grupo de personas -entre los que se encontraban editores, fotógrafos, diseñadores, artistas, entre otros- decidió reunirse y promover una acción de protesta y reflexión. Así, realizaron intervenciones performáticas en diferentes espacios de la Ciudad. La primera fue en el Pasaje Dardo Rocha y la Feria del Libro constituyó el hecho por el cual surgió el colectivo. Frente a la mirada sorprendida de feriantes, compradores y organizadores, este colectivo repitió varias veces una poesía que a la vez describía el desastre de la inundación y denunciaba la falta de responsabilidad en las acciones del Municipio y los medios de comunicación.

Parte de la poesía - gritada entre el ruido de la feria-, decía: "Desde la puñalada de la espalda, nos queda esta intemperie desmedida, de galopar de la crónica perfecta, la misma que los noticieros desafían, en su banquete diario de perversión y especuladora miseria”. La forma de pensar la acción poética estuvo relacionada con intervenir en un espacio público normalizado, mostrando la ausencia de acciones efectivas orientadas a resolver la situación de la población afectada por la catástrofe y también de los negocios y políticas urbanísticas que eran parte causal de la inundación. La operación literaria fue doble: exhibir lo que la política debería hacer y señalar su ineficacia. La poesía fue recitada varias veces desde diferentes lugares en el espacio de la Feria y rompía con la regla de no hablar de política, de la inundación, ni del intendente, mientras que en el lugar se subía el volumen de la música para que no fuesen escuchados. Para ese momento, sólo habían pasado dos meses desde la catástrofe y la prohibición se relacionaba con dos cuestiones. Por un lado, con el contexto de un duro cuestionamiento hacia el accionar previo, durante, y después de la inundación, por parte del entonces intendente Pablo Bruera. Por otra, porque era un tema de conversación recurrente, aun entre desconocidos.

La segunda intervención de La Marca del Agua se realizó en la Plaza Moreno de la ciudad de La Plata el día 2 de abril de 2014, al cumplirse un año de la inundación y en el marco del evento cultural Desbordes ${ }^{1}$ (Ver Figura 2). En la plaza central, rodeado de muchas actividades artísticas tendientes a realizar la denuncia contra el poder político, el grupo invitó a leer a quienes transitaban por allí. Repartieron copias a entre ochenta y cien personas que devinieron en ese instante en ciudadanos gritando poesía. Pero el ejercicio del grito no era ya porque había censuras institucionales como en la feria. Era un grito colectivo que señalaba a los culpables - por los contenidos de la poesía-.

Dos días después, el 4 de abril de 2014, tuvo lugar la tercera intervención en el marco de la inauguración de la muestra "Inundación y después", en el Museo de Arte y Memoria. En la muestra, como ya dijimos, se presentó una exposición de fotografías sobre la catástrofe, en la cual podía observarse los daños en la Ciudad. En el marco de esta actividad, se invitó al Juez Arias, quien había denunciado el ocultamiento de la cantidad de muertos, a disertar sobre su investigación. El enfrentamiento en este sentido se generó entre los organizadores que plantearon realizar la intervención dentro de un horario del cronograma mientras que la contrapropuesta de La Marca del Agua era generar sorpresa, a la vez que proponer como disertante a una persona que había estado en los barrios trabajando con intervenciones visuales, a través del proyecto "Volver a habitar". Ante la negativa de am- 


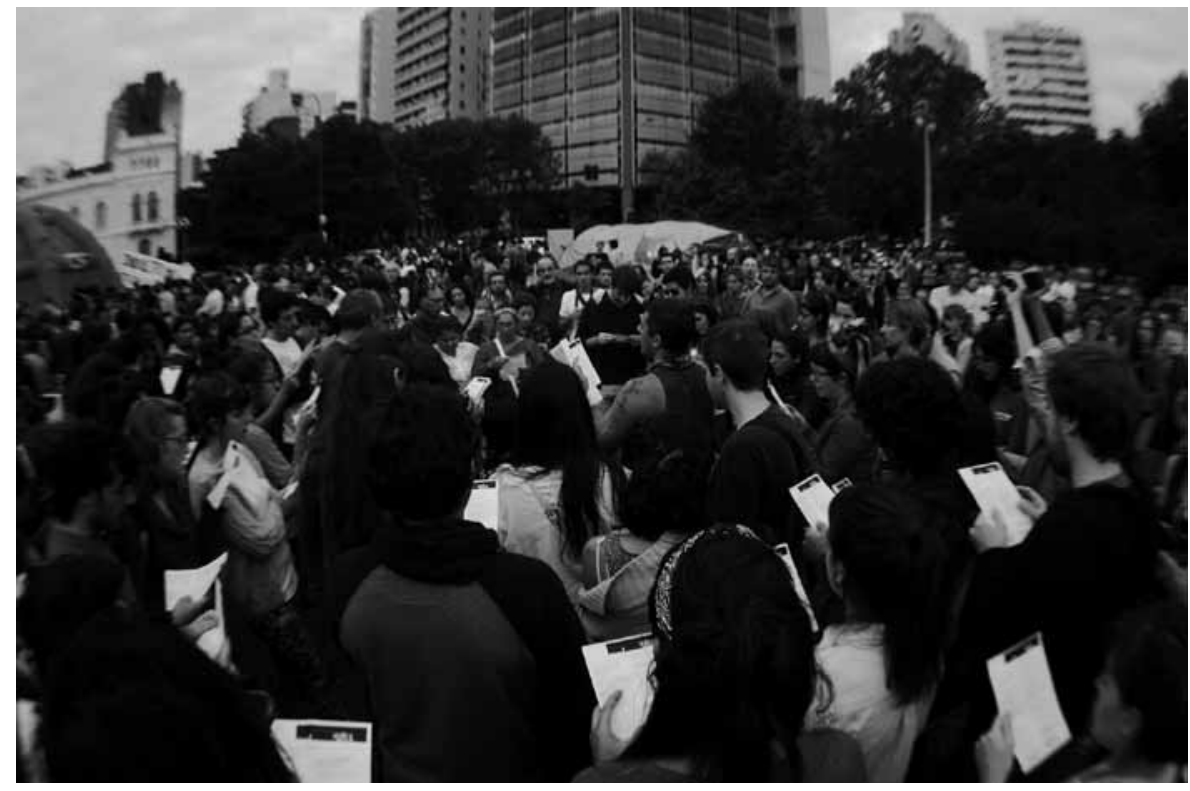

Figura 2. "Episodio 2". (La Marca del Agua, Plaza Moreno, 2014).

bas cuestiones, decidieron hacer la irrupción de todos modos. El colectivo invadió la sala leyendo una poesía y entregando copias al auditorio para que acompañaran con su voz. Algunos siguieron el texto con la vista, otros con el recitado. Luego, todos quedaron unos minutos en silencio. Los integrantes del grupo se retiraron y comenzó la exposición del Juez. El efecto sorpresa y de desacomodamiento fue nuevamente una de las características de las irrupciones artísticas del grupo, dado que evitaba que se sepa el momento exacto en que se iba a llevar a cabo el recitado a la espera que el espectador se corriera de su lugar asignado de expectación para participar activamente en la propuesta. Por último, el 14 de marzo de 2015, el grupo realizó una intervención y "volanteada" caminando por la calle 8 de la Ciudad, un lugar céntrico y muy concurrido, invitando a participar del evento a Desbordes 2015.

Todas las intervenciones performáticas fueron lecturas colectivas de textos poéticos, a diferencia de otras prácticas artísticas que ocurrieron en La Plata. Esto se hallaba en estrecha relación con que los integrantes formaban parte de las editoriales independientes locales: Pixel Editora, Club Hem Editores y Estructura Mental a las Estrellas. La elección del dispositivo poesía, entonces, estuvo relacionado con "el grupo editorial" (Entrevista a Agustina realizada por la autora, 09/04/2014) y con que consideraban que "llevar una poesía a la calle es más lindo que leer un discurso o un manifiesto: como que te lleva de la forma, la forma de leerlo, aparte, es diferente” (Entrevista a Guillermina realizada por la autora, 09/04/2014). 
Otra dimensión que caracterizó a las acciones directas del colectivo en cuestión es el lugar del espectador que, según cada caso, asumía la postura de observador o de partícipe activo en la práctica artística. Por último, y con relación a los espacios de intervención, siempre fueron públicos. Las acciones oscilaron entre el espacio público institucional -Pasaje Dardo Rocha, Museo de Arte y Memoria-, y el espacio público urbano -Plaza Moreno, calle 8-. Ello le aportó a cada acto características y desarrollos particulares. En suma, las intervenciones de La Marca del Agua pueden ser leídas como marcas de la memoria efímeras, que han aparecido en distintos espacios de la Ciudad, y que, por un lapso de tiempo, se escenificaron, al igual que en el próximo caso que analizaremos, en el cuerpo de quienes participaron en la propuesta.

\section{Performance y marcha por la ciudad de La Plata}

$\mathrm{Al}$ año de la inundación -el 2 de abril de 2014-, los colectivos Volver a habitar ${ }^{2}$, Intervenir $\mathrm{LP}^{3}$ y La Joda teatro ${ }^{4}$, junto con vecinos, artistas de la ciudad, Familiares de Víctimas de la inundación y la Asamblea de Asambleas barriales ${ }^{5}$ realizaron una performance por la ciudad de La Plata ${ }^{6}$, en la cual mediante el uso del cuerpo tradujeron, reelaboraron, recrearon e interpretaron el suceso. La intervención performática fue grabada y difundida en formato audiovisual vía YouTube -disponible hoy en día-, lo cual también muestra cómo los espacios virtuales, en tanto archivos, permiten reactivar en cualquier momento, el recuerdo, incluso si se trata de acciones efímeras.

En el video se puede ver la emoción y lágrimas de transeúntes al ver la intervención que remite a la inundación -en este sentido, la puesta en escena de la situación es un recurso que apunta a lo afectivo y sensorial para comprometer a los participantes-. En ella se muestra parte de la marcha que se realizó ese día, en la cual se ve una multiplicidad de símbolos desplegados como banderas, imágenes, flores y finalmente culmina con la siguiente frase o consigna: "por el esclarecimiento del número real de víctimas, por las obras hidráulicas necesarias, por la indemnización a los afectados y juicio político a los responsables".

Asimismo es interesante esta propuesta, a la vez simbólica y emotiva, porque culminó con el acto de depositar tres mil flores alrededor de las velas que la gente había colocado en las escaleras de la Catedral. Vemos aquí cómo aparece el acto de poner una flor como forma de homenaje (Ver Figura 3). Como mencionamos anteriormente, también vecinos y víctimas colocaron flores en el Monumento a las Víctimas de la inundación. En el caso de la performance se conjugaron flores y velas para recordar a quienes no estaban, acciones típicas utilizadas generalmente en rituales religiosos como velar o enterrar a un ser querido. Aquí, entonces, la memoria, más que apoyarse en un soporte que tienda a una marcación más o menos estable en el espacio, se constituyó en un "compromiso con el cuerpo y un modo alerta de la conciencia (...), un acontecimiento colectivo" (Schindel, 2009 , p. 84). Este tipo de prácticas existen en tanto hay individuos que las portan y, en este caso, la performance, "(igual que memoria, igual que trauma) es siempre una experiencia en el presente. Opera en ambos sentidos, como un transmisor de la memoria traumática y a la vez su re-escenificación”. (Taylor, 2009, p. 34) 


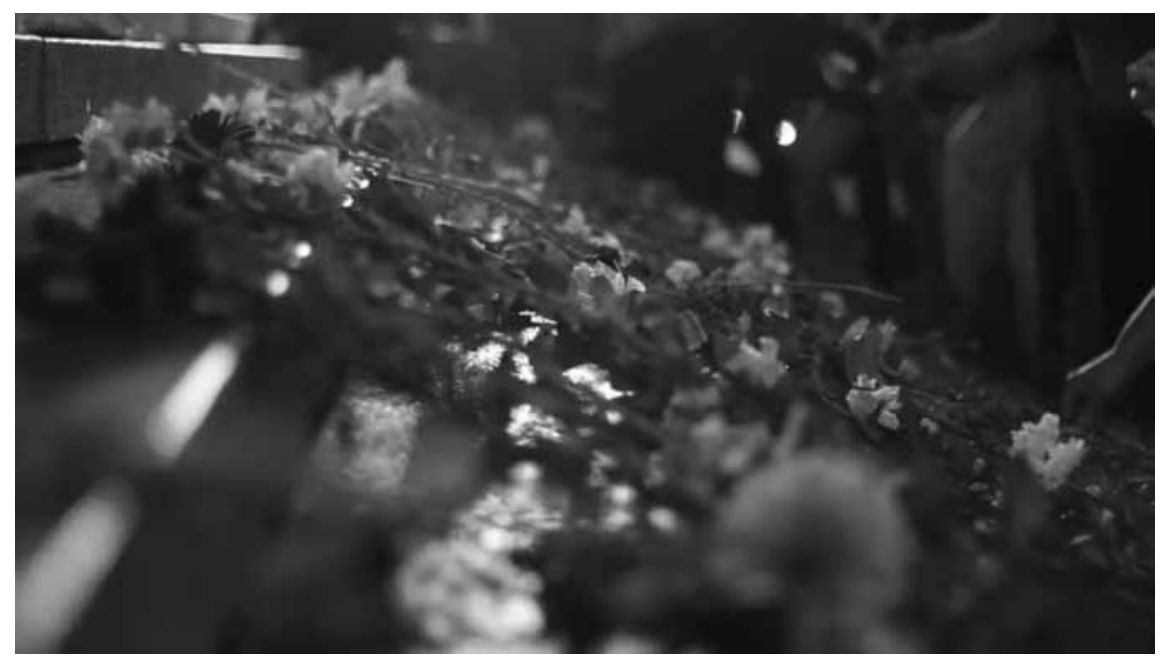

Figura 3. "Primer aniversario de la inundación del 2 de abril de 2013" (Plaza Moreno, 2014). Fuente: Intervención $2 \mathrm{~A}$

Esta acción puede ligarse al tipo de prácticas semejantes que suceden cuando hay casos de desapariciones de personas o muertes. Es decir, el recurso de las velas, las flores, las marchas, forman parte de un repertorio que se repite en situaciones similares. La originalidad de esta propuesta radicó en el soporte, que no fue un material estable, sino que encarnó en los cuerpos, en la perfomance. Como dijimos en un comienzo, estrategias locales y performáticas, por más que sean efímeras, también son marcas de la memoria en el espacio. En síntesis, hasta aquí vimos diversas modalidades de comunicación y de reactualización de la memoria luego del 2 de abril de 2013, unas efímeras, otras permanentes. Otra de estas modalidades son los aniversarios, es decir, las recordaciones anuales conmemorativas de determinados acontecimientos. Suele ser en esas fechas especiales en las que el recuerdo se reactualiza a partir de actividades comunes, colectivas y ritualizadas. Es por ello que en los tres casos aquí analizados, es relevante el momento y la fecha en que se realizaban las inicitivas artísticas. De esta forma, "pensar en la contundencia de los aniversarios" (Entrevista a Santiago, de Volver a habitar, 10/10/2017), formaba parte de una "estrategia comunicacional”, apuntando a la construcción de una memoria colectiva de la inundación.

\section{Consideraciones finales}

Luego de que un acontecimiento irrumpe y desestructura nuestra cotidianeidad y rutinas, puede aparecer la rememoración sobre ese hecho con el objetivo de darle un sentido y de narrarlo, lo cual se vincula con objetos e imágenes para hacerlo comunicable. En este 
sentido, nos parece interesante retomar la idea de la existencia de una "cultura material de las memorias" (Jelin 2017, p. 156) que aparece y se despliega en múltiples tipos de materialidades -edificios, documentos, lugares, trayectos urbanos de marchas, archivos, manifestaciones virtuales, cuerpos, etc.-, y que se instituyen como instrumentos para la reflexividad sobre acontecimientos pasados.

Se puede hablar entonces de diferentes tipos de prácticas de memoria, algunas, como vimos de carácter más o menos permanente, otras más dinámicas y efímeras. Esta idea se conjuga con que el recurso artístico empleado y la forma con la cual se plasma el recuerdo no siempre es la misma. Además sucede que estas marcas de memoria en el espacio público que, en este caso buscan exponer el recuerdo de la inundación, están sujetas a (re) interpretaciones, (re) actualizaciones y eventualmente a escenarios de confrontación y/o disputa. Así, el recuerdo que se realizó a partir del trabajo artístico -las performances, el monumento-, es habilitado por vía de diversos canales de expresión, una puesta en discurso mediado por imágenes y palabras. Concordamos con las palabras de Nelly Richard (2010), para quien

Les corresponde al arte, al pensamiento estético y crítico hacerse cargo de las subjetividades rotas y de las narraciones de los dañados que carecen de poder enunciativo en la esfera de los medios de comunicación, para que puedan inscribir en algún soporte pacientemente disponible los relatos vulnerables (...). Ahí encuentran su trama privilegiada de efectos y afectos. (p. 183)

Al respecto del arte, a partir de lo expuesto, podemos plantear dos cuestiones. En primer lugar, que el procesamiento del trauma, de "las subjetividades rotas" y de los "dañados", a veces es individual y otras colectivo. Si bien la producción artística devenida en marca de memoria es colectiva, hay diferencias entre quienes por un lado se acercan a partir de su vivencia personal -y por ejemplo colocan una flor o una vela en una marca de memoria- $y$, por otro, quienes participan de una producción artística colaborativa -aquellas propuestas en las cuales los vecinos o espectadores son partícipes activos, deviniendo productores. En este último caso, la tramitación es colectiva en tanto se acercan a la producción artística y forman parte de su elaboración a partir de compartir momentos con otros.

En segundo lugar, si bien el arte se posiciona como uno de los medios privilegiados para generar formas de rememoración -representaciones de la memoria, reconstrucciones, diseños y lenguajes visuales que se emplean para comunicar-, el debate estético también es parte constitutiva de los procesos de memoria. Con ello, hacemos referencia a que algunas marcas de memoria pueden contener mensajes literales y una estética mimética, mientras que no sucede lo mismo con otras.

También pueden existir conflictos entre quienes, como emprendedores de dichas marcas, producen determinada memoria visual y quienes no se sienten representados o identificados con ella, tal como vimos en el caso del Monumento a las Víctimas de la inundación. En este sentido, el acontecimiento visual que se genera entre la imagen y el espectador se constituye en un proceso que genera diversos sentidos y significaciones, que exceden a los esperados. Dimos cuenta de una pluralidad de espacios donde se despliegan las acciones de memoria: una calle, una plaza, un parque, el cuerpo. Esto nos permite ver que existen distintas dimensiones del espacio, el cual es construido y reconfigurado a partir 
de la inscripción de nuevas narrativas. A su vez, las prácticas artísticas como marcas de memoria, además de remitir a lo que pasó con la inundación y generar una reconfiguración de los espacios intervenidos, son relevantes en tanto lo que producen es también una reconfiguración temporal, del presente y del futuro. Es decir, muchas imágenes funcionan como soporte para el recuerdo, vivifican de una manera diferente, remiten al pasado pero interpelan desde el presente, contienen el tiempo de quien la mira e interpreta, además de poseer una expectativa de futuro. Es así que se puede hablar de un "montaje de tiempos heterogéneos", donde "la imagen a menudo tiene más de memoria y más de porvenir que el ser que la mira” (Didi-Huberman, 2006, p. 12). De esta forma, las imágenes no sólo funcionan como marcas de memoria, sino que además se configuran como un vehículo de ella. En síntesis, en cuanto a los espacios de despliegue de memoria, hicimos referencia a lugares físicos específicos, y al trayecto efímero de una marcha. Todos reconfigurados a partir de la inscripción de nuevas narrativas, marcas generadas desde la sociedad civil, relativas a la inundación. Estas propuestas llevaron adelante una reprogramación de la temporalidad; es decir, las producciones artísticas, como soporte para el recuerdo, referenciaron el pasado, interpelaron desde el presente y poseyeron una expectativa de futuro en su reactualización. También propusieron una "reconfiguración" de la memoria, o sea, otra memoria diferente a la memoria oficial -del Municipio y la Gobernación-, plasmando lo ocurrido, lo no dicho, lo ocultado, en un ejercicio de búsqueda de verdad y de justicia.

\section{Notas}

1. Desbordes es un evento artístico, cultural y comunicacional realizado desde el año 2014 para conmemorar los aniversarios de la inundación del 2 de abril de 2013, del cual participan distintos colectivos locales. Hasta el momento, cuenta con cuatro ediciones. Todos los eventos se llevaron a cabo en la Plaza Moreno, que es la plaza central de la ciudad y está ubicada frente al Palacio Municipal.

2. El colectivo artístico Volver a Habitar, realizó murales en distintos barrios afectados por la inundación y entrevistas a inundados con el objetivo de "restaurar comunidad", donde el mural era una excusa para un "ejercicio de memoria" colectivo.

3. Intervenir LP fue un ciclo de intervenciones socio/artísticas en el espacio público de la ciudad de La Plata que además realizó micros documentales sobre dichas acciones para difundir on-line. Para más información ver: https://www.youtube.com/user/intervenirLP 4. Tal como sostiene el colectivo en su página web, La Joda Teatro nace en 2007 con la intención de poner en crisis la noción clásica de escenario, retomando un concepto de teatro más participativo en el espacio público. Por lo tanto, se asume la necesidad de brindar funciones en centros culturales, facultades, clubs y -fundamentalmente- en la calle. En algunos casos, los límites entre la producción teatral y la performática se vuelven difusos. Para más información ver: https://lajodateatro.wordpress.com

5. La Asamblea de Asambleas barriales de La Plata agrupó a las distintas asambleas surgidas en diferentes barrios luego de la inundación del 2 de abril de 2013.

6. "Intervención 2A | Adelanto | Intervenir LP”. Recuperado de: https://www.youtube. com/watch?v=MY-TLcgEqyw. 


\section{Referencias Bibliográficas}

Battiti, F. (2007). “Arte contemporáneo y trabajo de memoria en la Argentina posdictadura”. En: Buchenhorst, R E Lorenzano, S (org.). Políticas de la memoria. Tensiones en la palabra y la imagen, (309-321). Buenos Aires, Argentina: Ed. Gorla.

Battiti, F. (2013). "Las exposiciones como formas de discurso. Algunas consideraciones sobre las muestras de artes visuales en los espacios de memoria en la Argentina. Revista de Instituciones, Ideas y Mercados. Buenos Aires, Argentina.

Cabutti, M. (2014). “Mirá cuántos barcos aún navegan”. Recuperado de: http://superbiastudios.com/art/marcela-cabutti/

Didi-Huberman, G. (2006). Ante el tiempo: historia del arte y anacronismo de las imágenes. Buenos Aires, Argentina. Ed: Adriana Hidalgo.

Foster, R. (2002). “La memoria como campo de batalla”. En: Puentes, $\mathrm{N}^{\circ}$ 8. Buenos Aires, Argentina. Centro de Estudios de la Memoria, La Plata.

Gianera, P (2002). “El arte puede plantear nuevas preguntas". Entrevista a Andreas Huyssen. En Puentes, No 8. Buenos Aires, Argentina. Centro de Estudios de la Memoria, La Plata.

Giménez, G. (2009). "Cultura, identidad y memoria. Materiales para una sociología de los procesos culturales en las franjas fronterizas". En: Frontera Norte. Buenos Aires, Argentina.

Gutiérrez Viñuales, R. (2004). Monumento conmemorativo y espacio público en Iberoamérica. Madrid, España: Ed. Cátedra.

Halbwachs, M. (1990). “Espacio y memoria colectiva”. En: Revista Estudios sobre las culturas contemporáneas. Buenos Aires, Argentina.

Jelin, E. (2001). “¿De qué hablamos cuando hablamos de memoria?” En: Los trabajos de la memoria. Madrid, España: Ed. Siglo Veintiuno editores.

Jelin, E. (2017). La lucha por el pasado. Cómo construimos la memoria social. Buenos Aires, Argentina: Ed. Siglo Veintiuno editores.

Jelin, E. y Langland, V. (2003). "Introducción: las marcas territoriales como nexo entre pasado y presente". En: Jelin, E. y Langland, V. (comps.) Monumentos, memoriales y marcas territoriales. Madrid, España: Ed. Siglo Veintiuno editores.

López Mac Kenzie, J. y Soler, M. (2014). El naufragio de La Plata. La Plata, Buenos Aires: Ed. La Pulseada.

Pollak, M. (1989). "Memoria, olvido y silencio". Texto publicado originalmente en portugués en la Revista Estudios Históricos. Río de Janeiro, No 3. Esta traducción es de uso interno del curso de posgrado en Antropología de la Memoria y la Identidad. Maestría en Historia y Memoria de la UNLP. Traducción de Renata Oliveira.

Richard, N. (2007). Fracturas de la memoria. Arte y pensamiento crítico. Buenos Aires, Argentina: Ed. Siglo Veintiuno editores.

Richard, N. (2010). Crítica de la memoria (1990-2010). Santiago de Chile, Chile: Ed. Universidad Diego Portales.

Richard, N. (2014). Diálogos latinoamericanos en las fronteras del arte: Leonor Arfuch, Ticio Escobar, Néstor García Canclini, Andrea Giunta. Santiago de Chile, Chile: Ed. Universidad Diego Portales.

Schindel, E. (2009). "Inscribir el pasado en el presente: memoria y espacio urbano". En: Política y Cultura, (31), 65-87. México. 
Taylor, D. (2009). "El espectáculo de la memoria: trauma, performance y política”. Teatro al sur, 15, 33-40.

Résumé : En prenant pour cadre l'inondation survenue dans la ville de La Plata, Buenos Aires, Argentine, le 2 avril 2013, cet article propose d'aborder diverses pratiques artistiques collectives ayant produit des traces mémorielles dans l'espace public. S'incarnant et se déployant selon des modalités matérielles diverses, ces propositions artistiques ont été instituées comme instruments de réflexion sur la catastrophe. Il s'agira d'examiner les caractéristiques des choix esthétiques, les différends sur la localisation et le type de représentations générées, ainsi que les luttes pour la construction d'une mémoire collective, toujours d'actualité quatre ans plus tard.

Mots-clés : Pratiques artistiques - Marques de mémoire - Inondation - La Plata - Espace public.

Abstract: In this paper we analyze collective artistic practices that, after the flood suffered by the city of La Plata -Buenos Aires, Argentina- on April 2, 2013, produced memory marks in the public space. From multiple types of materialities, these artistic proposals reflected the catastrophe. We will see the characteristics of the aesthetic choices, the disputes surrounding the location and the type of generated representations will be analyzed, as well as the struggles for the construction of a collective memory that still remains valid four years later.

Keywords: Artistic practices - Memory marks - Flood - La Plata - Public space.

Resumo: Esta pesquisa tem como objetivo abordar várias práticas artísticas coletivas que depois da inundação que sofreu a cidade de La Plata -Buenos Aires, Argentina-, no 2 de abril de 2013, produziram marcas de memória no espaço público. Com base em múltiplos tipos de materialidades, essas propostas artísticas foram instituídas como instrumentos para refletir sobre a catástrofe. Serão analisadas as características das escolhas estéticas, das disputas sobre a localização e o tipo de representações geradas, bem como as lutas pela construção de uma memória coletiva que ainda permanece válida quatro anos depois.

Palavras chave: Práticas artísticas - Marcas de memória - Inundações - La Plata - Espaço público.

[Las traducciones de los abstracts al francés, inglés y portugués fueron supervisadas por el autor de cada artículo] 